\title{
UNIQUE POSITIVE SOLUTION FOR NONLINEAR CAPUTO-TYPE FRACTIONAL $q$-DIFFERENCE EQUATIONS WITH NONLOCAL AND STIELTJES INTEGRAL BOUNDARY CONDITIONS
}

\author{
Ahmad Y. A. Salamooni and D. D. PaWAR
}

Abstract. This paper contains a new discussion for the type of generalized nonlinear Caputo fractional $q$-difference equations with $m$-point boundary value problem and Riemann-Stieltjes integral $\tilde{\alpha}[x]:=\int_{0}^{1} x(t) d \Lambda(t)$. By applying the fixed point theorem in cones, we investigate an existence of a unique positive solution depends on $\lambda>0$. We present some useful properties related to the Green's function for $m$ - point boundary value problem.

Mathematics subject classification (2010): 26A33, 34B15, 39A13, 33D05.

Keywords and phrases: Fractional $q$-difference equations, generalized Caputo type, boundary value problem, Riemann-Stieltjes integral, Green's function, existence, fixed point theorem.

\section{REFERENCES}

[1] F. JACKSON, On q-functions and a certain difference operator, Trans. Roy. Soc. Edinb. 46,(1908), 253-281.

[2] C. Adams, On the linear ordinary q-difference equation, American Math. Ser. Proc. Camb. Philo. Soc. 30, (1929), 195-205.

[3] W. Al-SAlam, Some fractional q-integrals and q-derivatives, Proc. Edinb. Math. Soc. 15, (1966), $135-140$.

[4] R. P. Agarwal, Certain fractional q-integrals and q-derivatives, Proc. Cambridge Philos. Soc. 66, (1969), 365-370.

[5] B. Ahmad, S. Ntouyas, A. Alsaedi, H. Al-Hutami, Nonlinear q-fractional differential equations with nonlocal and sub-strip type boundary conditions, Electron. J. Qual. Theo. Differ. Equ. 26, (2014), 1-12.

[6] W. Cheng, J. Xu, Y. CUI, Positive solutions for a system of nonlinear semipositone fractional qdifference equations with q-integral boundary conditions, J. Nonlinear. Sci. Appl. 10, (2017), 44304440.

[7] B. Ahmad, S. Etemad, M. Ettefagh, S. Rezapour, On the existence of solutions for fractional q-difference inclusions with q-antiperiodic boundary conditions, Bull. Math. Soc. Sci. Math. Roumanie. 59, (2016), 119-134.

[8] M. H. ANNABy, Z. S. Mansour, q-fractional calculus and equations, Lecture Notes in Mathematics 2056, Springer-Verlag, Berlin, 2012.

[9] P. M. Rajković, S. D. Marinković, M. S. Stanković, On q-analogues of Caputo derivative and Mittag-Leffler function, Fract. Calc. Appl. Anal. 10, (2007), 359-373.

[10] P. M. Rajković, S. D. Marinković, M. S. Stanković, Fractional integrals and derivatives in q-calculus, Appl. Anal. Discret. Math. 2007, 1, 311-323.

[11] W. Yang, Y. Qin, Positive Solutions for Nonlinear Caputo Type Fractional q-Difference Equations with Integral Boundary Conditions, Mathematics 2016, 4, 63; doi:10.3390/math 4040063. www.mdpi.com/journal/mathematics.

[12] C. ZHAI, J. REN, Positive and negative solutions of a boundary value problem for a fractional $q$ difference equation, Adv. Differ. Equ. 2017: 82. 
[13] J. REN, C. ZHAI, A fractional q-difference equation with integral boundary conditions and comparison theorem, Int. J. Nonlin. Sci. Num. 18, (2017), 575-583.

[14] J. REN, C. ZHAI, The unique solution for a fractional q-difference equation with threepoint boundary conditions, Indagat. Math. New. Ser. 29, (2018), 948-961.

[15] A. A. Kilbas, H. M. SRivastava, J. J. Trujillo, Theory and Applications of Fractional Differential Equations, Elsevier, Amsterdam (2006).

[16] C. ZhaI, F. WANG, Properties of positive solutions for the operator equation Ax $=\lambda x$ and applications to fractional differential equations with integral boundary conditions, Adv. Differ. Equ. 2015:366. 